\title{
Negotiation communication revisited
}

\author{
Mareike Schoop ${ }^{1}$ (1)
}

Accepted: 30 November 2020 / Published online: 22 January 2021

(c) The Author(s) 2021

\begin{abstract}
Negotiators communicate with each other and decide on offers or requests. Whilst the decision side of negotiations has long been a focus of negotiation research, the communication side has not been extensively supported. The current paper revisits the need for a communication perspective in business negotiations and reviews current research on negotiation communication. Both strands of relevant work are then integrated to provide a concept of electronic negotiation communication and to discuss how this concept was implemented in the system Negoisst and thus operationalised.
\end{abstract}

Keywords Negotiation communication - Electronic negotiation · Language-action perspective $\cdot$ Negoisst

\section{Introduction}

Negotiation-digital or non-digital-is a process of communication and decision making. Negotiators make offers, counter-offers, requests, explain their statements, compliment or threat the negotiation partner, accept or reject the offer at hand. These communicative acts are integrated with decision acts, namely which particular offer to make, which value to accept or reject for a negotiation issue, which alternative to choose, which improvements to make etc. The main motivation for a negotiation is that the partners cannot reach their goals by themselves; rather they need the other party for that. A negotiation is, therefore, an intertwined process; negotiators always depend on their partner. That holds for both communication and decision making. For example, it has been shown that communicative behaviour (such as threats, insults, or niceties) leads to a mirror effect, i.e. the negotiation partner will communicate accordingly (Schoop et al. 2014). Concession making can equally be reciprocal, i.e. a larger concession leads to a greater willingness by the negotiation

Mareike Schoop

schoop@uni-hohenheim.de

1 Information Systems Group, University of Hohenheim, Stuttgart, Germany 
partner to make concessions; the opposite also holds true (e.g. Vetschera 2016a, b). The result of a negotiation process is a compromise if a consensus can be reached.

Whilst decision support has long been researched and is the more structured and formalised part of negotiation, communication support has been less researched as it is the richer but also the more flexible part of negotiation.

In this paper, we will revisit negotiation communication from two angles. The first is a communication perspective that is rooted in communication theories and views negotiation as a specific form of communication. The second is a negotiation perspective that views communication as one part of negotiation. These two strands of research will then be integrated to revisit negotiation communication in 2020 and beyond. An operationalisation of such integrated concept of negotiation communication is presented by introducing the negotiation support system (NSS) Negoisst. Finally, the contributions and challenges of communication support in (electronic) negotiations are discussed.

\section{The communication perspective}

Negotiation is communication and decision making. A good negotiator is thus somebody who can communicate clearly, appropriately, convincingly, and who is empathic because they understand that negotiators depend on each other. Furthermore, a good negotiator is somebody who can make the right decisions, choose the best alternatives, offer appropriate deals, and make concessions whenever necessary.

In their seminal paper, Weigand et al. (2003) argue for the need for a communication perspective in business-to-business negotiation support. Whilst decision making has been well supported, communication has not seen much dedicated support.

\subsection{Habermas, Searle, and the language-action perspective}

The arguments of Weigand et al. (2003) are shaped by the works of Habermas, Searle, and the language-action perspective.

The Theory of Communicative Action by Habermas (1981) is seen as his main contribution to assessing the meaning of communicative action for society (McCarthy 1984). Strategic action is oriented towards achieving individual goals. The communicator wants the communication partner to agree on what would be favourable to the communicator. Sometimes deception or power are used to achieve the desired effect. In contrast, communicative action is oriented towards mutual understanding. The communicator interacts with the communication partner to achieve a common background and reach mutual agreement. Here, interaction between the communication partners is essential. In Habermas' view, communicative action is the positive form of action whereas strategic action is seen as negative or at least less favourable. Therefore, communicative action should be performed and supported.

To conceptualise mutual understanding, Habermas introduces four so-called validity claims that are raised with an utterance: (1) comprehensibility, (2) truth, (3) truthfulness, (4) appropriateness. 
(1) An utterance is comprehensible if the hearer understands the speaker. If comprehensibility is problematic, then the hearer will not understand the speaker, e.g. because unknown words are used or because the speaker cannot be heard. An example would be to use different professional terminologies in a negotiation so that the partners do not understand (some of) each other's terms. Comprehensibility problems are solved through using other words that are known to the hearer, through defining what is meant by an unknown word, through translating, through switching to a different (professional) terminology, or through using the appropriate medium for an utterance.

(2) An utterance is true if the hearer shares the speaker's knowledge. If truth is problematic, then the hearer will take the utterance to be false, e.g. because a fact is incorrect or because an implicit precondition is unknown to the hearer. An example would be a negotiator claiming that a product needs to fulfil a certain standard assuming that the standard is universal. The recipient of such message might evaluate this utterance to be false because such standard does not exist in their country. Communication problems concerning truth are solved by providing more information on the statement and thus explaining why the utterance is true after all.

(3) An utterance is truthful if the hearer believes the speaker. If truthfulness is problematic, then the hearer will think that the speaker lies. Communication problems concerning truthfulness add a personal layer to the communication problem because challenging the truthfulness of an utterance means challenging the sincerity of the speaker. Truthfulness problems are thus inter-personal problems and require careful assurance of sincerity by the speaker and consistent actions.

(4) An utterance is appropriate if the hearer agrees with the speaker on norms, standards, and values guiding the utterance. If appropriateness is problematic, then the hearer does not believe the speaker to have the appropriate role to make such speech act. Communication problems concerning the validity claim of appropriateness are solved by referring to unproblematic norm and standards and by citing acknowledged experts for support.

If problems regarding truth and appropriateness cannot be solved through discussion, communicators can enter into a discourse which is an ideal speech situation with all participants having equal rights and are not constrained, e.g. by position, rank, experience etc. Theoretical discourse deals with truth; practical discourse deals with appropriateness.

Speech Act Theory by Searle (1969) classifies utterances into five classes.

Assertives state facts about the objective world as, for example, in statements, reports, remarks, summaries, introductions. Commissives represent the speaker's intention to carry out an action that is described in the utterance as, for example, in promises, pledges, assurances, guarantees, vows. Directives represent the speaker's attempt to get the hearer to carry out an action as described. Examples are requests, orders, demands, questions. Expressives represent the speaker's psychological states and attitudes as, for example, in apologies, condolences, insults, compliments, 
regrets. Declaratives represent an institutionalised speech act which changes a state of affairs. Examples are sentencing a prisoner, declaring a couple to be lawfully married, conveying a doctorate to a candidate, appointing an applicant.

The different classes of utterance are related to the validity claims as follows. Assertives must be understood by the hearer who needs to agree on the utterance. Therefore, the claims of comprehensibility and truth are the ones raised when one makes an assertive speech act. Commissives are about the speaker's commitment to an action whereas directives represent the hearer's commitment to an action. They must be comprehensible and sincere and appropriate. A speaker would not be expected to commit to an action they and the hearer knew they could not fulfil; a hearer would not be expected to be committed to an action that was requested to ridicule them. Expressives represent the speaker's psyche and must be comprehensible and sincere. If an apology is taken to be half-hearted, it will not be accepted. Declaratives as normative speech acts must be comprehensible and, in addition, they must be appropriate. A lay person cannot sentence a suspect so this would be an inappropriate speech act.

Habermas' critical theory and Searle's speech act theory shaped a new approach to organisational communication, called the language-action perspective (LAP) (Flores and Ludlow 1980; Schoop 2001; Winograd 1988; Winograd and Flores 1987). The assumptions are that language is action and thus has a performative as well as a descriptive character and that people are fundamentally communicative beings (Schoop 2001).

LAP has also shaped information systems and in particular the conceptual design and implementation of information systems (Dietz and Widdershoven 1991; Lyytinen 1985; Lyytinen and Klein 1985). It is argued that the main task of an information system is to support organisational communication, thereby empowering people to enter into meaningful and open conversations to prevent misunderstandings and to achieve (communicative) goals.

\subsection{The need for a communication perspective}

Based on Searle's speech act classification and Habermas' validity claims, Weigand et al. (2003) introduce three types of negotiations.

Norm-based negotiations aim to achieve an agreement via authorisation/obligation. There are formalised types of negotiation following clear protocols. For example, a request-for-quote is a formally defined directive speech act that carries an obligation for the recipient to send a quote. Such quote then carries an authorisation for the recipient to buy as quoted and for the sender to sell for the conditions offered in the quote. Such norm-based negotiations were the state-of-the-art in early electronic negotiation processes as they were relatively easy to support and didn't pose a grand challenge. The interaction is very formal and there is a minimal amount of communication involved.

In contrast, goal-based negotiations see the negotiators being motivated by goals rather than positions. Such negotiations allow all partners to challenge the other's position and to enter into discussions. It is important to find out the reasons for a 
particular offer or rejection and to be open to questions or criticism by the partner. The interaction is flexible and there is a significant amount of communication involved.

Document-based negotiations focus on the exchange of formalised documents such as contract templates and contain communication for explaining questions or the required changes in contract versions. Again, the process of interaction is a very structured one but one that is enriched through communication.

Both norm-based and document-based negotiations mainly carry the validity claim of appropriateness. The norms that are the basis for norm-based negotiations can be challenged which means that the appropriateness of such declarative speech acts is questionable. The contract documents in document-based negotiations can also be challenged in terms of their content appropriateness for the current state of negotiation. Both types also raise the validity claim of comprehensibility which is a claim that is raised in any type of communication.

Goal-based negotiations are rich communicative interactions. Therefore, all validity claims can be challenged depending on the type of speech act that is made as discussed above. A discussion on both the content and the mode of interaction is possible. Apart from comprehensibility, a negotiator can challenge the truth of an offer claiming to show the market price or they can challenge the truthfulness of a take-it-or-leave-it offer because they don't believe it will be the last offer or they can challenge the appropriateness of a tit-for-tat strategy by questioning whether the negotiation partner has the authority to make big concessions.

\section{The negotiation perspective}

Negotiation cannot be performed without communication as communication is the essence of negotiation and bargaining. Tutzauer (1992) argues that there is offer communication and non-offer communication. Offer communication is the pure exchange of offers and counter-offers. It is obvious that there must be offer communication for each negotiation process (Schoop and Reiser 2007). Non-offer communication comprises of the arguments, explanations, apologies, preferences, emotions, information etc. They are vital for the mutual understanding about facts and positions, about correlations between the negotiation items, and about norms, values, and rules that the negotiation process and the social process are expected to obey.

When it comes to electronic negotiations, the medium plays a vital role. Deterministic approaches argue that the medium determines the outcome. For example, Social Presence Theory (Short et al. 1976) argues that the degree of social presence is equal to degree of awareness of the other person in a communication interaction. Therefore, an electronic medium has a lower degree of social presence. Media Richness Theory (Daft and Lengel 1986) argues that there is a right medium for a given collaboration task. A complex task needs to be supported by a rich medium. If an inappropriate medium is chosen, there is either too much irrelevant information which will distract the communicator or too few cues for interpretation which will lead to misunderstandings. Non-deterministic approaches argue that communicators 
have learned to adapt to different types of media to compensate for missing cues in electronic media so that complex communicative exchanges can take place electronically. For example, the Technology Acceptance Model argues that users presented with a new system are influenced by how much they believe using the system would enhance their performance and these benefits would outweigh the effort of learning to use the system (Davis 1989).

Körner (2019) shows that an identical negotiation case negotiated using the identical system leads to very different communicative and economic outcomes by different negotiators. Therefore, the deterministic view cannot be valid for electronic negotiations.

The negotiation perspective is a largely decision-oriented perspective. Although negotiations are defined as consisting of communication and decision making, the decision making dominates the negotiation research. Reviewing negotiation systems, the decision perspective has also long dominated this type of system research. The first systems to support electronic negotiations were decision support systems (Jarke et al. 1987; Jelassi and Foroughi 1989). Much of the negotiation research by Vetschera has a decision-analytic focus (e.g. Engin and Vetschera 2017; Filzmoser and Vetschera 2008; Vetschera 2016a, b to name but a few). From a more design-oriented perspective, the focus of Kersten has also been on decision support in negotiation support systems (NSSs) (e.g. Carbonneau et al. 2016; Kersten 1989). The well-known NSS Inspire which has been much used in negotiation teaching is a decision-based system that offers little communication support (Kersten and Noronha 1999). Dedicated communication support that goes beyond message exchange (Yuan et al. 1998) is still scarce (Schoop 2010).

Compared to research on decision making and decision support, research on negotiation communication and communication support is less formalised and structured and must take the richness of language into account. However, it is vital given the definition of negotiation as communication and decision making as the following examples show.

Schoop et al. (2010) analyse communication quality in e-negotiations and develop a communication quality measure for negotiation processes. It consists of effectiveness, efficiency, and relationship management. Effectiveness measures the degree of shared understanding of task and structure and whether the outcome (i.e. reject or accept) makes sense given the last offer. Efficiency represents whether discussions could clear up misunderstandings, whether the process had unwanted latencies, and whether the utterances were interrelated. Relationship management measures mutual trust, the negotiation climate, the satisfaction with oneself and the partner, and the enjoyment of the process. Duckek (2010) shows that a high communication quality leads to economic benefits such as lower transaction costs and more straightforward and conclusive and thus more cost-effective processes.

Communication in negotiations does not always have to be formal. Indeed, many deals have been prepared or advanced during coffee breaks. In a project on businessto-business electronic negotiation support for architects and small and medium-sized trade companies (such as plasterers, roofers, plumbers), the need for supporting informal communication in addition to formal negotiation communication became apparent. It was important for the negotiators to step away from the formal arena 
into an informal one where possibilities could be discussed without issuing formal requests or offers (Schoop 2002).

Negotiation communication is not only about the values of issues at hand. Rather, there is often also meta-communication concerning the issues themselves or, more generally, the negotiation agenda (Fernandes et al. 2013). At the start of a negotiation process, the negotiation partners need to agree on what they will negotiate about. They thus set up the negotiation agenda. Information that is gathered during a negotiation, external constraints that limit the negotiation freedom, or the strategic retention of negotiation goals might and in most cases will lead to changes to the negotiation agenda. If such changes are not enabled in negotiation systems, then these systems do not support the communication sufficiently which has been shown to lead to less favourable outcomes (Fernandes 2016).

Both essential parts of a negotiation can lead to conflicts. Decision conflicts arise when insufficient concessions are made and at least one of the partners does not believe in the possibility of a deal. Communication conflicts arise when the communication is impolite, threatening or breaches norms or expectations. To find out whether communication conflicts or decision conflicts have a larger impact on the likelihood and quality of an agreement, Schoop et al. (2014) report on an e-negotiation experiment analysing such conflict types. One group of students negotiated with a uniform opponent (which they were unaware of) who was very polite but made only small concessions. This group was thus exposed to a decision conflict. The second group of students negotiated with a uniform opponent (which they were also unaware of) who was impolite to the point of being insulting but made large concessions. This group was thus exposed to a communication conflict. The third group was a control group negotiating with each other. It was shown that the communication conflict was the most threatening one for reaching an agreement. A polite partner who was tough on concessions still got away with a higher number of deals and a higher satisfaction of their partners whereas the negotiators faced with a communication conflict were dissatisfied although they could and indeed often did strike a good deal. This shows how important the support of communication is in negotiations as communication is the vital factor for success or failure in negotiations.

\section{Taking stock}

Almost 20 years ago, Weigand et al. (2003) argued that there needs to be a communication perspective in negotiations. Based on established communication theories and on a communicative approach to information systems, they designed three concepts of electronic negotiations that have different communicative intensities and different levels of formality. The main conclusion is that the communication perspective is underrepresented in negotiation research and thus needs to be applied to negotiation research and negotiation systems.

Twenty years later, the communication perspective is still underrepresented in negotiation research. There are only few studies on negotiation communication and communication support in negotiation systems although it was shown that communication problems will often lead to bad or no outcomes at all. 
Therefore, there must be a dedicated communication support, especially in negotiation systems dealing with the challenges of 2020 and beyond. The next section will show the synthesis of the two strand of work on communication in negotiations, namely the communication perspective and the negotiation perspective.

\section{The synthesis}

Having discussed the communication perspective and the negotiation perspective, we will now synthesise both into an overall model of electronic negotiation communication and discuss its implementation.

\subsection{Negotiation communication}

Whilst the concept of integrative negotiation is usually seen as an economic concept where both parties get a mutually benefit deal and thus a win-win result, we argue that there is also an integrative communication paradigm.

The overall goal of negotiation is mutual understanding. To ensure this, negotiators must constantly work on preventing misunderstandings that could lead to severe communication problems and in the worst case be the cause of a negotiation failure. Therefore, rich negotiation processes must take place that enable and even encourage discussions, challenges, and the discovery of mutual benefits. To ensure mutual understanding, the negotiators must develop their common background and will negotiate about meanings of utterances. To this end, grounding will be used as a communicative method (Duckek 2010). When an utterance is made, it is not enough to wait for a reply. Rather, it is important to receive or ascertain feedback to assure that the negotiation partner understood what was said. If the partner does not understand (because there was a comprehensibility problem) or does not agree (because there was a problem with truth or appropriateness) or does not trust the negotiator (because there was a problem with truthfulness), then these problems with the validity claims associated with the utterance must be solved (cf. Sect. 2.1). Furthermore, the communication processes themselves need to be negotiated. It is important to retain the communication thread during a complex and often lengthy negotiations. To this end, coherence is important (Duckek 2010). The overall theme must be retained which is global coherence. Referring to a specific topic, to specific utterances, or to parts of an utterance helps the negotiators to interpret negotiation messages in the intended way, e.g. there must be answers when questions are raised. In general, utterances have to be connected to previous ones in an orderly and meaningful way. By communicating, relationships can be built and maintained (Duckek 2010). If a negotiator does not communicate, the relationship with the negotiation partner will break down. The way a negotiator communicates shows what kind of relationship exists and how important that (professional) relationship is for the negotiator. Relational communication can be performed in different ways. For example, offering information and being cooperative enhances trust. Exchanging personal information ("schmoozing") enables the negotiation partner to relate. Social norms 
are followed; for example, if a negotiator finds an offer unfair or a message offensive, the author should apologise. Relational communication thus negotiates the norms and rules that form a relationship. These three types of negotiation are all meta-negotiations, i.e. negotiations about communication (cf. Duckek 2010; Schoop et al. 2010), see Fig. 1.

The individual goals are reached by using effective and efficient negotiation communication (cf. Sect. 3). In particular, the negotiation system must support rich communication exchanges. This will be the subject of the following section.

\subsection{System support of negotiation communication}

A negotiation support system must support the richness of negotiation. That means that both communicative action and strategic action must be enabled. Communicative action is particularly important for meta negotiation communication (cf. Fig. 1). Strategic action will sometimes be performed for achieving individual negotiation goals.

To enable rich exchanges that are open to challenges and explanations, conflict and solutions, threats and compliments, there must be a possibility to solve problems with validity claims. The negotiation support system Negoisst (Schoop et al. 2003; Schoop 2010) is a system that is rooted in the language-action perspective. It offers maximum support whilst retaining maximum flexibility of the negotiators. The negotiation protocol provides a structure that helps to interpret utterances (e.g. as an informal information or a formal offer) and provides transparency. Validity claims can be discussed in an informal negotiation area. Figure 2 shows the negotiation protocol. The negotiation begins in the start state and ends either with an acceptance or a rejection. The informal states are questions and clarification.

The negotiation speech acts shown in Fig. 2 are related to the classification of speech acts by Searle (1969), cf. Sect. 2.1. Offers and counteroffers are commissives; requests and questions are directives; clarifications are assertives; rejects and accepts are declaratives. Questions and clarifications represent the informal messages that were requested by the professional negotiators (cf. Sect. 3) and that represent a virtual coffee/tea break.

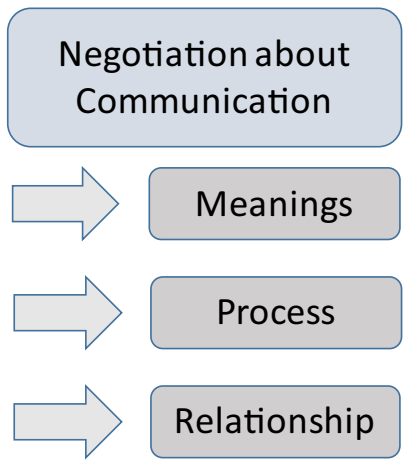

Fig. 1 Meta negotiation communication 


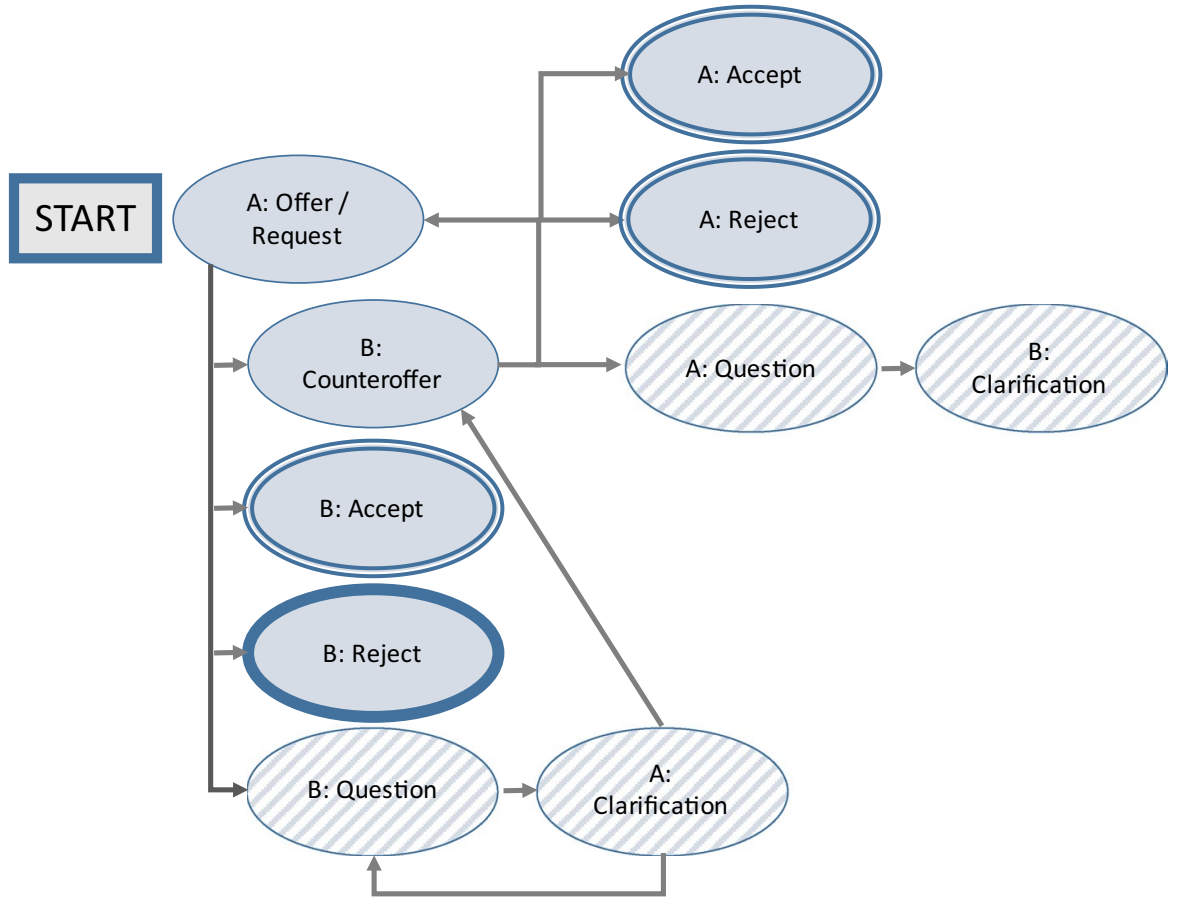

Fig. 2 Negotiation protocol with formal and informal negotiation states

Enabling the discussion of validity claims enables what Weigand et al. (2003) call goal-oriented negotiations. However, Negoisst also supports more formal and structured negotiations, be they norm-oriented or document-oriented. This ensures maximal flexibility.

The meta negotiation communication to ensure mutual understanding is also represented in the system, see Fig. 3. Grounding is supported in two ways. Firstly, each message carries a message type that explicitly shows the intention of the sender and thus provides the common ground for interpretation. Secondly, the negotiation communication message can be semantically enriched. That means that the natural language text can be linked to the structured negotiation ontology that provides the definitions of the negotiation issues at hand. This enables the grounding of the negotiation issues whilst not restricting the message text.

Of course, negotiators must seek to achieve grounding and coherence in every single negotiation message. As the system does not restrict the use of terms in any way, the negotiators are responsible for ensuring mutual understanding and for being aware of any communication problems which can then be discussed in the informal negotiation area. We are on the way to a proactive communication system which will advise negotiators on the risk of a negotiation failure based on an automated emotion pattern recognition (Kaya and Schoop 2019, 2020; Körner 2019). 


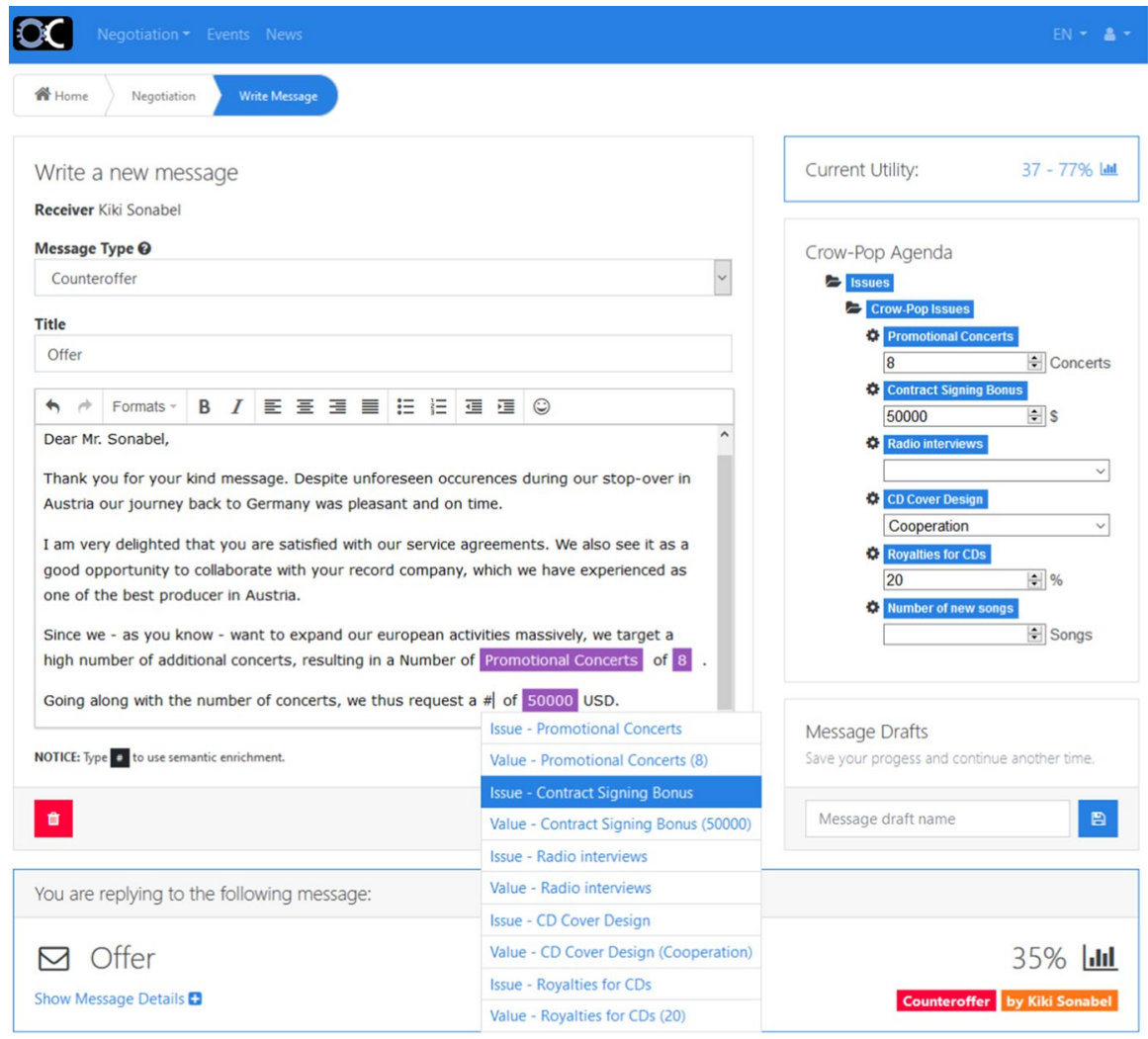

Show all messages in chronological order $\boldsymbol{t}$

Fig. 3 Grounding of negotiation communication in Negoisst (Schoop 2010)

It is important to state that Negoisst certainly offers decision support as well as conflict management and document management. However, these are not the focus of this paper and were discussed elsewhere (Schoop 2010; Schoop et al. 2004).

\section{Conclusion}

Whilst negotiation definitions acknowledge that negotiations consist of communication and decision making, research has been less balanced. Almost 20 years after Weigand et al. (2003) called for a communication perspective in negotiations, there is still a shocking lack of communication support in negotiation support systems other than Negoisst and in negotiation concepts in general. Negotiation quality is partly communication quality and partly a beneficial agreement.

The assessment of the interplay of communication and decision making in electronic negotiations shows that communicative conflicts are the most problematic type of conflict in electronic negotiations (Schoop et al. 2014). If there are 
communication conflicts, then there is a higher likelihood of no or an unfavourable agreement compared to the occurrence of decision making conflicts, e.g. too few concessions made by the partner. It was shown that the existence of decision support in an NSS does not lead to a focus on the relationship. This is what communication does and what NSSs must provide in terms of communication support. Likewise, decision support does not lead to more integrative behaviour. Again, good communication can help to find integrative deals. This shows the importance of the communication perspective. It also shows that 18 years after the work by Weigand et al. (2003), there is still a need for such perspective in negotiation support systems.

With the technological advances of machine learning, communication support can even be proactive in NSSs. By automatically analysing and evaluating communication messages in electronic negotiations, predictions are possible as to whether an ongoing process is likely to end in agreement or not (Kaya and Schoop 2019, 2020) which is one of the grand challenges of communication-focused NSS research that we are currently working on.

Acknowledgements I would like to thank my research assistants and $\mathrm{PhD}$ students who have contributed to the much needed communication support in Negoisst. I am proud to be part of this issue celebrating my esteemed colleague Professor Rudolf Vetschera. I have had the pleasure of working with Rudolf for many years and our collaboration has turned into a friendship that I value tremendously. I have always admired Rudolf's intellect, ideas, and enthusiasm as well as his kindness and empathy. This is to many more years of joint research!

Funding Open Access funding enabled and organized by Projekt DEAL.

Open Access This article is licensed under a Creative Commons Attribution 4.0 International License, which permits use, sharing, adaptation, distribution and reproduction in any medium or format, as long as you give appropriate credit to the original author(s) and the source, provide a link to the Creative Commons licence, and indicate if changes were made. The images or other third party material in this article are included in the article's Creative Commons licence, unless indicated otherwise in a credit line to the material. If material is not included in the article's Creative Commons licence and your intended use is not permitted by statutory regulation or exceeds the permitted use, you will need to obtain permission directly from the copyright holder. To view a copy of this licence, visit http://creativecommons.org/licen ses/by/4.0/.

\section{References}

Carbonneau R, Vahidov R, Kersten G (2016) Quantitative concession behavior analysis and prediction for decision support in electronic negotiations. Int J Decis Support Syst Technol 6(4):16-30

Daft RL, Lengel R (1986) Organizational information requirements, media richness and structural design. Manag Sci 32(5):554-571

Davis F (1989) Perceived usefulness, perceived ease of use, and user acceptance of information technology. MIS Q 13(3):319-340

Dietz JLG, Widdershoven GAM (1991) Speech acts or communicative action? In: Proceedings of the second European conference on computer-supported cooperative work, ECSCW 91, pp 235-248

Duckek K (2010) Ökonomische Relevanz von Kommunikationsqualität in elektronischen Verhandlungen. Gabler, Wiesbaden

Engin A, Vetschera R (2017) Information representation in decision making: the impact of cognitive style and depletion effects. Decis Support Syst 103:94-103

Fernandes M (2016) Agenda negotiations in electronic negotiation support systems: an information systems perspective. Books on Demand, Norderstedt 
Fernandes M, Melzer P, Gettinger J, Schoop M, van der Wijst P (2013) Agenda negotiations in an electronic negotiation support system. In: Proceedings of group decision and negotiation 2013, pp 234-237

Filzmoser M, Vetschera R (2008) A classification of bargaining steps and their impact on negotiation outcomes. Group Decis Negot 17(3):421-443

Flores F, Ludlow JJ (1980) Doing and speaking in the office. In: Fick G, Sprague RH Jr (eds) Decision support systems: issues and challenges. Pergamon Press, London, pp 95-118

Habermas J (1981) Theorie des kommunikativen Handelns. Suhrkamp Verlag, Berlin

Jarke M, Jelassi MT, Shakun MF (1987) MEDIATOR: towards a negotiation support system. Eur J Oper Res 31(3):314-334

Jelassi MT, Foroughi A (1989) Negotiation support systems: an overview of design issues and existing software. Decis Support Syst 5:167-181

Kaya MF, Schoop M (2019) Application of data mining methods for pattern recognition in negotiation support systems. In: Morais D, Carreras A, de Almeida A, Vetschera R (eds) Group decision and negotiation: behavior, models, and support. Lecture notes in business information processing. Springer, Berlin, pp 223-237

Kaya MF, Schoop M (2020) Maintenance of data richness in business communication data. In: Proceedings of the 28th European conference on information systems (ECIS 2020). https://aisel.aisnet.org/ ecis2020_rp/189. Accessed 15 Jan 2021

Kersten G (1989) Expert system technology and strategic decision support. Math Comput Model $12: 1321-1333$

Kersten GE, Noronha SJ (1999) WWW-based negotiation support: design, implementation and use. Decis Support Syst 25:135-154

Körner M (2019) Sentiment analysis in electronic negotiations. University of Hohenheim. http://opus.unihohenheim.de/volltexte/2019/1617/. Accessed 15 Jan 2021

Lyytinen K, Klein HK (1985) The critical theory of Jürgen Jabermas as a basis for a theory of information systems. In: Mumford E, Hirschheim RA, Fitzgerald G, Wood-Harper AT (eds) Research Methods in Information Systems. Elsevier, North-Holland, New York, pp 207-226

Lyytinen K (1985) Implications of theories of language for information systems. MIS Quarterly 9(1):61-74

McCarthy T (1984) The critical theory of Jürgen Habermas. MIT Press, Cambridge

Schoop M (2001) An introduction to the language-action perspective. ACM SIGGROUP Bull 22(2):3-8

Schoop M (2002) Electronic markets for architects - the architecture of electronic markets. Inf Syst Front 4:285-302

Schoop M (2010) Support of complex electronic negotiation. In: Kilgour M, Eden C (eds) Handbook of group decision and negotiation. Springer, Berlin, pp 409-423

Schoop M, Reiser A (2007) Analysing strategy patterns of offer communication in electronic negotiations. Proceedings of Group Decision and Negotiation 2007:279-292

Schoop M, Jertila A, List T (2003) Negoisst: a negotiation support system for electronic business-tobusiness negotiations in E-Commerce. Data Knowl Eng 47(3):371-401

Schoop M, Köhne F, Staskiewicz D (2004) An integrated decision and communication perspective on electronic negotiation support systems: challenges and solutions. J Decis Syst 13(4):375-398

Schoop M, Köhne F, Ostertag K (2010) Communication quality in electronic negotiations. Group Decis Negot 19(2):193-209

Schoop M, van Amelsvoort M, Gettinger J, Koerner M, Koeszeig ST, van der Wijst P (2014) The interplay of communication and decisions in electronic negotiations: communicative decisions or decisive communication? Group Decis Negot 23:167-192

Searle JR (1969) Speech acts-an essay in the philosophy of language. Cambridge University Press, Cambridge

Short J, Williams E, Christie B (1976) The social psychology of telecommunications. Wiley, London

Tutzauer F (1992) The communication of offers in dyadic bargaining. In: Putnam L, Roloff M (eds) Communication and negotiation. Sage, Newbury Park, pp 67-82

Vetschera R (2016a) Concessions dynamics in electronic negotiations: a cross-lagged regression analysis. Group Decis Negot 25:245-265

Vetschera R (2016b) Deriving rankings from incomplete preference information: a comparison of different approaches. Eur J Oper Res 258(1):244-253

Weigand H, Schoop M, de Moor A, Dignum F (2003) B2B negotiation support: the need for a communication perspective. Group Decis Negot 12:3-29 
Winograd T (1988) A language/action perspective on the design of cooperative work. In: Greif I (ed) Computer Supported Cooperative Work: A Book of Readings. Morgan Kaufmann, San Mateo, pp $623-653$

Winograd T, Flores F (1987) Understanding computers and cognition: a new foundation for design. Addison-Wesley Longman Publishing Co., Boston

Yuan Y, Rose JB, Suarga S, Archer NP (1998) A web-based negotiation support system. Int J Electron Mark 8(3):13-17

Publisher's Note Springer Nature remains neutral with regard to jurisdictional claims in published maps and institutional affiliations. 